\title{
Tecnologias digitais e ensino remoto: reflexões outras sobre as precariedades diante da pandemia
}

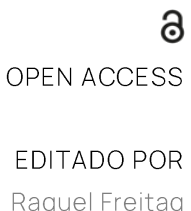

Raquel Freitag

AVALIADO POR

Noádia Silva

SOBRE OS AUTORES Nádson Araújo dos Santos Contribuiu com Roseane Araújo dos Santos. Papéis: escrita rascunho original, análise e edição.

Roseane Araújo dos Santos Contribuiu com Nádson Araújo dos Santos. Papéis: escrita rascunho original, análise e

edição.

DATAS

Recebido: 11/07/2020 Aceito: $08 / 08 / 2020$ Publicado: 17/08/2020

COMO CITAR

Santos, N. A.; Santos, R. A.

(2020).

Tecnologias digitais e ensino remoto: reflexões outras sobre as precariedades diante da pandemia. Revista da Abralin, v. 19, n.

2, p. 1-5, 2020.
Nádson Araújo dos SANTOS (D

Universidade Federal de Alagoas (UFAL)

Roseane Araújo dos SANTOS @

Centro Universitário Cesmac (CESMAC)

\section{RESUMO}

A fala da professora Ana Elisa Ribeiro, intitulada Tecnologias Digitais: ciclos da precariedade diante da pandemia, ocorreu em 25 de junho de 2020, durante a série de conferências e mesas-redondas denominada Abralin ao Vivo - Linguists Online, uma iniciativa da Associação Brasileira de Linguística (ABRALIN). O objetivo da conferência foi refletir sobre a precariedade instalada nas escolas brasileiras, em especial, quanto à apropriação das tecnologias digitais por parte dos professores e da escola. Bem como, refletir sobre os problemas de acesso e as desigualdades sociais existentes entre os alunos, fatores que impulsionaram uma reflexão sobre como a escola tem enfrentado tais dificuldades no ensino remoto. Modalidade oferecida pela maioria das instituições de ensino no Brasil em tempos de pandemia.

\section{ABSTRACT}

The speech by professor Ana Elisa Ribeiro, entitled Digital Technologies: cycles of precariousness in the face of the pandemic, occurred on June 25, 2020 during a series of conferences and round tables called Abralin ao Vivo - Linguists Online, an initiative of the Brazilian Association of Linguistics (ABRALIN). The purpose of the conference was to reflect on the 


\section{REVISTA DA ABRALIN}

precariousness installed in Brazilian schools, especially regarding the appropriation of technologies by teachers and the school. As well as the problems of access and how social inequalities exist among students, factors that stimulated a reflection on how the school has faced such difficulties in remote education, a teaching modality offered by most educational institutions in Brazil in times of pandemic.

PALAVRAS-CHAVE

Tecnologias Digitais. Precariedade. Ensino Remoto.

KEYWORDS

Digital Technologies. Precariousness. Remote Teaching.

A fala da professora Ana Elisa Ribeiro, intitulada Tecnologias Digitais: Ciclos da Precariedade Diante da Pandemia, ocorreu em 25 de junho de 2020, durante a série de conferências e mesas-redondas promovidas pela Abralin, de forma on-line. Ribeiro inicia a conferência fazendo uma reflexão sobre a atualidade da temática: Tecnologias Digitais e Pandemia, tendo em vista o atual cenário educacional que tem se instalado no Brasil devido à crise causada pela pandemia da Covid-19. A autora discorre sobre a repentina e emergente necessidade de mudança no modo pelo qual as escolas começaram a ofertar educação em todo o país.

Em sua fala inicial, Ribeiro (2020), explica que o modelo adotado pela maioria das escolas brasileiras foi o ensino remoto e faz questão de frisar que esta modalidade de ensino não pode ser confundida com a educação à distância $(\mathrm{EaD})$ ou o ensino online. A palestrante continua expondo que no Brasil as escolas apresentam, geralmente, estruturas físicas precárias: salas de aula mal ventiladas, lotadas e carentes de tecnologias digitais. Ribeiro destaca que esse cenário de precariedade, é uma realidade desde antes da pandemia e que o atual cenário pandêmico tem acentuado ainda mais as necessidades estruturais dessas escolas, sobretudo, de tecnologias digitais, tanto do ponto de vista de acesso, quanto ao de formação.

Nesse ponto, concordamos com a professora, pois pesquisas realizadas nos últimos anos (SANTOS; CAVALCANTE, 2020), têm demonstrado as precariedades das escolas brasileiras, sobretudo, da escola pública. Professores e alunos enfrentam dificuldades no acesso às tecnologias digitais, sendo esse um dos grandes problemas para o efetivo trabalho com os gêneros digitais e para a ampliação do letramento digital dos alunos (SANTOS, 2019).

Ribeiro continua sua fala apresentando as principais precariedades enfrentadas pelas escolas durante a pandemia. Primeiramente, expõe que as escolas não possuíam um Ambiente Virtual de Aprendizagem (AVA) bem estruturado, além de uma internet de péssima qualidade e problemas de acesso aos sistemas de informação. Ana Elisa Ribeiro destaca que, num cenário de aulas presenciais, 


\section{REVISTA DA ABRALIN}

anterior à pandemia, a maioria das escolas apresentavam como recursos digitais e tecnológicos disponíveis em sala, um projetor digital fixo (sem computador) e outros equipamentos obsoletos. A autora faz uma crítica importante quando defende que, até março de 2020, esse tipo de equipamento era observado como um avanço nas práticas pedagógicas, quando, na verdade, já apontavam para a precariedade enfrentada pelos sistemas de ensino no Brasil.

Sabemos que a maioria das escolas do nosso país não possui uma quantidade adequada de dispositivos tecnológicos em seus laboratórios de informática, e isso contribui para que não atendam de modo efetivo a quantidade de alunos matriculados nessas unidades. Pesquisas revelam que professores sentem dificuldades em realizar atividades que utilizam tecnologias digitais, isso se dá pelo fato de as escolas possuírem laboratórios com computadores obsoletos e em número reduzido (SANTOS, 2019).

Outra questão importante que a autora destaca, é que em 2019 se discutia muito os problemas de desigualdades referentes ao acesso às tecnologias digitais, nesse momento da conferência, Ribeiro destaca o caso do menino de Recife, que sem acesso a dispositivos digitais e internet, recorre a uma loja de telefonia móvel de um importante shopping da capital pernambucana, para realizar suas atividades de pesquisa. Ribeiro (2020), nos leva a refletir: onde estaria o garoto hoje? Quem estaria dando assistência a esse tipo de sujeito? Como estão enfrentando a pandemia os "nativos digitais"? Prensk (2010), defende como concepção de nativo digital, o sujeito nascido na era das tecnologias. No entanto, queremos destacar que no Brasil existe uma série de fatores que precisam ser considerados para aferir tal natividade, em nosso país, não é a idade que determina se o sujeito é um nativo digital ou não, pois, outras questões, como as desigualdades sociais e a falta de acesso devem ser considerados . Sabemos que em nosso país, enfrentamos sérios problemas de desigualdades socioeconômicas, sendo assim, em nossa realidade sociocultural, não podemos compreender como "nativo digital", o sujeito que nasceu (apenas) na sociedade moderna, pois sabemos que muitos destes jovens, não possuem acesso às tecnologias digitais em suas residências.

Ana Elisa Ribeiro, continua sua conferência destacando que durante a pandemia da Covid-19, as tecnologias digitais começaram a serem utilizadas também como apoio para a medicina e à família, nos casos de acesso virtual aos doentes impossibilitados de receberem visitas de seus parentes, fato que foi noticiado em importantes veículos de comunicação brasileiros e internacionais.

Ribeiro nos provoca a pensar que para alguns, o cenário da pandemia tem levado a enfrentamentos de dificuldades, para outros, a necessidade de enfrentar novos desafios. Nesse sentido, questiona: dificuldades ou desafios de quem? Nesse momento, a conferencista discorre sobre os enfrentamentos dos sujeitos que necessitam utilizar-se das tecnologias digitais para ter acesso às aulas remotas, por exemplo. A autora acrescenta que se exigiu outros imaginários sobre as Tecnologias Digitais da Informação e Comunicação (TDIC), pilotagens e incipiências. Novos imaginários, relacionados aos usos radicais, imprevistos e improvisados das TDIC, para realizar a educação remota nesse período de pandemia. A professora destaca que todo esse movimento de ressignificação das práticas docentes tem levado a refletirmos o depois, ou seja, o pós-pandemia.

A conferencista continua sua fala, refletindo sobre as pesquisas realizadas pelos programas de pós-graduação, sobre os relatos de experiências que tinham como objeto de estudo, os usos das 


\section{REVISTA DA ABRALIN}

tecnologias digitais na educação, provocando assim, uma reflexão sobre a continuidade desses projetos e pesquisas e seu legado para os enfrentamentos da atualidade. Desse modo, questiona: em que medida a educação se apropriou das TDIC (antes)? O que imaginávamos fazer? Após realizar a reflexão de como nos apoiamos nas pesquisas realizadas antes pandemia, a autora faz outro questionamento muito importante: em que medida a educação se apropriou das TDIC (agora)? O que vai ser aprendido? O que vai ser abandonado? Esses questionamentos são provocações para que os professores reflitam sobre o que esse momento de necessidades de apropriação das TDIC tem ensinado sobre práticas docentes para o retorno das atividades no futuro. Continuaremos realizando as práticas antigas? Abandonaremos as experiencias e aprendizados dos enfrentamos à pandemia e a repentina necessidade do ensino remoto? São algumas questões que a fala de Ribeiro nos leva a refletir.

Seguindo, Ribeiro expõe sobre os usos radicais das TDIC, a plataformização realizada por muitas unidades escolares na criação dos seus AVAs, com isso, questionamos: como serão utilizados esses ambientes virtuais no futuro? Haverá uma continuidade de seus usos? A professora continua discutindo sobre a qualificação "adequada" para os professores. Se é que há alguma formação adequada para o enfrentamento às pandemias. No entanto, nesse momento, cabe a questão: quando foi que nos qualificamos para os usos das tecnologias digitais? Nas licenciaturas? Nas especializações? Nos cursos livres? Quanto tempo tivemos para isso? Ribeiro afirma que no Brasil, nós tivemos pelo menos trinta anos para nos qualificar e buscar a formação. A fala da professora é uma crítica à formação inicial e continuada de professores e suas carências, sobretudo, para a apropriação das tecnologias digitais para usos pedagógicos.

Diante do exposto, a professora aponta que há, pelos menos, duas grandes precariedades enfrentadas pela educação durante a pandemia da Covid-19: a falta de estrutura (equipamentos, softwares, rede) e a falta de formação (graduada ou outra). Mesmo enfrentando tanta precariedade, a autora defende que os educadores estão se saindo muito bem.

Nesse ponto, assim como Riberio, entendemos que há uma lacuna enorme no que se refere a formação de professores para as tecnologias digitais aqui no Brasil e o reflexo disso é observado no receio que muitos professores têm em utilizar metodologias ativas no ensino (FILATRO; CAVALCANTI, 2018) e no desenvolvimento do letramento digital para práticas sociais na cultura digital (LÉVY, 2010).

A conferencista continua sua apresentação retomando a questão dos usos improvisados dos estudantes no período da pandemia: sem banda larga, sem conexão, o que exige de todos, uma nova organização do tempo e da vida. Ribeiro destaca que a Base Nacional Comum Curricular (BNCC, 2017), é um documento que aponta a todo tempo para os usos das tecnologias digitais na escola.

Ribeiro encerra sua apresentação, apontando que se abstrairmos o problema epidemiológico, a pandemia da Covid-19, pode ser um momento de experimentação e mudanças, pode ser também um momento para apresentar a quem sempre resistiu, momento de pensar com cuidado nas consequências, de rever ideias, escritos, pensamentos e é momento para se realizar pesquisas. Oportunidades de rever e refazer, de enxergar nosso contexto, de dispensar o que não nos cabe. Se faz necessário ainda, pensar localmente, agir com recursos globais. Pensar em uma melhor infraestrutura para as escolas e na formação de professores. 


\section{REVISTA DA ABRALIN}

Ressaltamos a pertinência da conferência e a atualidade da temática, recomendamos aos professores, alunos e demais profissionais da educação que assistam a palestra. Certamente, ela irá contribuir significativamente para a formação e a reflexão pessoal e profissional de cada um, bem como, sobre as práticas pedagógicas de enfrentamento durante a pandemia.

\section{REFERÊNCIAS}

BRASIL. Ministério da Educação (MEC). Base Nacional Comum Curricular. Brasília: 2017. Acesso em: 08 fev. 2020. Disponível em: <http://basenacionalcomum.mec.gov.br/images/BNCC_EI_EF_110518_versaofinal_site.pdf>. Acesso em: 08 mar 2020.

EDUCAÇÃO e tecnologias digitais: ciclos da precariedade diante da pandemia. Conferência apresentada por Ana Elisa Ribeiro. [s.l., s.n], 2020. 1 vídeo (1h 33min 25seg). Publicado pelo canal da Associação Brasileira de Linguística. Disponível em: https://www.youtube.com/watch?v=_-lfTZT7oFI. Acesso em: 25 jun 2020.

FILATRO, A; CAVALCANTI, C. C. Metodologias inov-ativas na educação presencial, a distância e corporativa. 1.ed. São Paulo: Saraiva Educação, 2018.

LÉVY, P. Cibercultura. Tradução de Carlos Irineu da Costa. 3.ed. São Paulo: Editora 34, 2010.

PRENSKY, M. Teaching digital natives: partnering for real learning. Tradução de Stephen Heppell. Corwin: Califórnia, 2010.

SANTOS, N. A. Das páginas às telas: o lugar do (não) lugar dos gêneros digitais no livro didático de Português. 2019. 108 f. Dissertação (Mestrado em Educação) - Centro de Educação, Programa de Pós-Graduação em Educação, Universidade Federal de Alagoas. Maceió, 2019.

SANTOS, N. A.; CAVALCANTE, M. A. S. Gêneros digitais em livros didáticos de português: uma abordagem focada no livro didático e na concepção de professores. fólio - Revista de Letras, v. 12, n. 1, 2020. DOI: https://doi.org/10.22481/folio.v12i1.6338. 